\title{
Modeling endogenous learning and imperfect competition effects in climate change economics
}

\author{
Laurent Viguier • Leonardo Barreto • Alain Haurie • \\ Socrates Kypreos • Peter Rafaj
}

Received: 26 October 2004 / Accepted: 9 November 2005 / Published online: 13 October 2006

(C) Springer Science + Business Media B.V. 2006

\begin{abstract}
In this two-part paper we evaluate the effect of "endogenizing" technological learning and strategic behavior of agents in economic models used to assess climate change policies. In the first part we show the potential impact of R\&D policies or demonstration and deployment (D\&D) programs in the context of stringent stabilization scenarios. In the second part we show how game-theoretic methods can be implemented in climate change economic models to take into account three types of strategic interactions: (i) the market power of the countries benefiting from very low abatement costs on international markets for $\mathrm{CO}_{2}$ emissions, (ii) the strategic behavior of governments in the domestic allocation of $\mathrm{CO}_{2}$ emissions quotas, and (iii) the non-cooperative behavior of countries and regions in the burden sharing of $\mathrm{CO}_{2}$ concentration stabilization. The two topics of endogenous learning and game-theoretic approach to economic modeling are two manifestations of the need to take into account the strategic behavior of agents in the evaluation of climate change policies. In the first case an R\&D policy or a demonstration and deployment (D\&D) program are put in place in order to attain a cost reduction through the learning effect; in the second case the agents (countries) reply optimally to the actions decided by the other agents by exploiting their strategic advantages. Simulations based on integrated assessment models illustrate the approaches. These studies have been conducted under the Swiss NCCR-Climate program.
\end{abstract}

Keywords Endogenous technological learning · Strategic behavior · Climate policy · Emissions trading $\cdot$ Economic models $\cdot$ Dynamic games

\footnotetext{
L. Viguier $(\bowtie)$

Ecole Polytechnique Fédérale de Lausanne (EPFL), Switzerland; MIT Joint Program on the Science and Policy of Global Change, Cambridge, MA, USA

e-mail: laurent.viguier@epfl.ch
}

L. Barreto · S. Kypreos

Paul Scherrer Institute, Villigen, Switzerland

\author{
A. Haurie \\ HEC-Geneva, Switzerland
}

P. Rafaj

International Institute for Applied Systems Analysis, Laxenburg, Austria 


\section{Introduction}

In this paper we propose different ways to introduce strategic decision making in the economic models used for the global assessment of climate policies. The paper summarizes several examples of models including strategically behaving agents that have been developed in the realm of the NCCR-Climate research program. ${ }^{1}$

In general, model-based assessments of climate policy assume a competitive framework, and emissions targets are supposed to be reached through cost-effective economic instruments (i.e. uniform carbon tax or economy-wide emission trading regime). However, many recent studies in environmental economics focused on strategic behaviors, incentive problems, and transaction costs associated with information, implementation, learning, administration, monitoring, and compliance (Hahn 1984; Stavins 1995; Goulder and Mathai 2000). A strategic behavior is obtained when the economic agents take into action the reaction of the system or of the other agents to their proposed policies. A first set of examples we present is related to the learning effect of new technologies introduction in the economy. A technology which is currently too costly to penetrate the market could become attractive if enough investment is done due to the learning effect. Therefore a planner should take into account this learning response in the design of an R\&D policy or demonstration and deployment (D\&D) programs. However due to the introduction of increasing returns to scale associated with the learning effect one cannot count on an "invisible hand" to guide the economy purely from market signals. The R\&D and D\&D efforts are strategic in the sense that it is done in the purpose of exploiting the learning curve and thus reaching lower costs levels.

Other studies in climate economics focused on market imperfections such as pre-existing taxation (Babiker et al. 2003, 2004; Goulder and Mathai 2000), and the role of strategic behaviors in policy implementations, i.e. exemptions and subsidies (Babiker et al. 2003). Game theoretic models in climate change policy assessment have been considered in very aggregated qualitative models (Carraro and Siniscalco 1996; Barrett 1997; Germain et al. 1998), with an emphasis on the stability and credibility of commitments. They have also been used recently to evaluate the possibility to establish a linkage between climate policies and other issues related to international negotiations (Carraro and Siniscalco 1996; Barrett 1999). The game-theoretic approach has also been applied to assess the effects of $\mathrm{CO}_{2}$ market imperfections in the realm of current Kyoto Protocol implementation (Bernard et al. 2005, 2003; Haurie and Viguier 2003).

In this paper, we explore the representation of strategic behavior in three categories of models, namely an optimal economic growth models like MERGE (Manne and Richels 2001), a multi-region bottom-up process model like MARKAL (Fishbone and Abilock 1981; Loulou and Lavigne 1996), and a multi-region computable CGE model like GEMINI-E3 (Bernard and Vielle 1998, 2003). These three classes of models have been used by the economic analysis group of the NCCR-Climate to produce an integrated assessment of climate policies in conjunction with climate and climate-change impact models produced by other groups of the research network (see the companion paper on coupling). The paper is therefore organized in two parts. In the first part we show selected examples of endogenous technological learning (ETL) in the MERGE5 model and a multi-regional energy-system model (GMM) for assessing the impact of technological learning in atmospheric $\mathrm{CO}_{2}$ stabilization scenarios. In the second part of the paper we address the problem of representing three types of strategic interactions in IAMs: (i) market power in international emission trading, (ii) strategic behavior

\footnotetext{
${ }^{1} \mathrm{~A}$ research network on climate supported by the Swiss NSF. 
of government during the initial allocation of emission quotas across sectors, and (iii) strategic behavior of competing agents (nations) that are parties to the international negotiations on climate policies and have to share the burden of stabilizing $\mathrm{CO}_{2}$ concentration in the long run.

\section{Modeling endogenous learning in an IAM}

In this first part we show how to endogenize technological learning in MERGE, an IAM that includes a "bottom-up" representation of the energy supply sector (Kypreos 2000, 2005; Kypreos and Bahn 2002; Manne and Barreto 2004) and also in GMM, a multi-regional energy system model (Barreto 2001; Rafaj et al. 2005). These studies evaluate the economic advantages of endogenous and induced learning via public and private RD\&D spending in support of carbon-free generation technology. The method investigated herein prescribes early R\&D support and learning investments in carbon-free systems to aid these technologies to follow learning curves. This dedicated RD\&D spending influences developments during the demonstration and deployment phases and reduces the cost of new technologies. We assume that public RD\&D spending of research institutes, together with the research investments of industries that act as global players, creates knowledge that can be compensated and appropriated via market diffusion and uptake of these new technological systems on the global level.

\subsection{Technological learning in the MERGE model}

As mentioned above, technological learning describes how the specific cost of a given technology is reduced through the accumulation of knowledge with respect to that technology. This learning process evolves either from manufacturing and operation of the technology (LBD) or research-and-development (LBS) expenditures allocated to that technology. A learning curve relates the specific cost incurred by a given technology to one or more factors describing the accumulation of knowledge in that technology. In MERGE, these factors are taken as the cumulative power generation in the one-factor learning curve, and the cumulative R\&D expenditures in the two-factor learning curve. A number of ETL systems for electric and non-electric technologies have been introduced into MERGE (Bahn and Kypreos 2002; Kypreos 2000, 2005; Kypreos and Bahn 2002; Manne and Richels 2002). The first generic learning technology modeled in MERGE, corresponding to power generation and the second technology referring to a non-electric energy system. We have assumed for LBD that a $15 \%$ cost reduction is incurred for each doubling in production, and a $10 \%$ cost reduction for each doubling in the knowledge stock. Also, a barrier is introduced to represent a maximum possible reduction of generating cost of (e.g., 50 mills per $\mathrm{kWh}$ for electric backstop systems and 6 US\$/GJ for the non-electric backstops). All technologies and the non-learning costs associated with these backstop systems, which represent the balance of plant, are assumed to be encompassed in an autonomous cost reduction at a rate of $0.5 \%$ per annum.

\subsubsection{The Two Factor Learning Curve (TFLC)}

The section describes the inclusion of endogenous technological learning in MERGE5, using the TFLC formula (e.g., with Learning-by-Doing and Learning -by- Searching components) (Criqui and Viguier 2000; Kouvaritakis et al. 2000). In the two-factor learning curve, the cumulative production (output) is used as a proxy for the accumulation of experience that 
affects the specific investment cost of a given technology. Similarly, the knowledge stock, defined as the accumulation of a depreciated R\&D spending, is used to determine cost reductions attendant to LBS processes. For example, the learning curve for the cost of electricity generation $G C_{k, t}$ (in US\$ per MWh or US\$ per GJ) of a technology $k$ is defined as

$$
G C_{k, t}=a \cdot C P_{k, t}^{-b} \cdot K S_{k, t}^{-c}
$$

where $C P_{k, 0}$ is the cumulative production, and $K S_{k, t}$ stands for the knowledge stock estimated as the depreciated sum of annual $R \& D$

$$
K S_{k, t}=K S_{k, t-1} \cdot(1-s)+R D_{k, t} \cdot y p p_{t}
$$

where $R D_{k, t}$ is the annualized research and development spending, $s$ is the depreciation factor, and $y p_{t}$ the number of year per period.

The $a$ parameter can be calibrated by applying equation 1 for the initial point of the learning curve $\left(G C_{k, 0}, K S_{k, 0}, C P_{k, 0}\right)$, and the $b$ and $c$ parameters are the learning indices. The latter define the speed of learning and are derived from the learning ratio. The learning ratio $l r$ is the rate at which the generating cost declines each time the cumulative capacity doubles, while $\operatorname{lr} s$ is the rate at which the cost declines each time the knowledge stock doubles. The relation between $b, c, l r$ and $l r s$ can be expressed as follows:

$$
\begin{aligned}
1-l r & =2^{-b} \\
1-l r s & =2^{-c} .
\end{aligned}
$$

For the introduction of LBD and LBS options and learning subsidies into the model, a few new variables and equations are defined. The cumulative production, $C P_{k, t}$, is based on the annual generation of unsubsidized, $P E_{k, t}$, and the amount of subsidized electricity production, $S P E_{k, t}$ :

$$
\begin{aligned}
C P_{k, t}= & C P_{k, t-1}+0.5 \cdot\left(P E_{k, t} \cdot y p p_{t}+S P E_{k, t} \cdot y p p_{t}\right. \\
& \left.+P E_{k, t-1} \cdot y p p_{t-1}+S P E_{k, t-1} \cdot y p p_{t-1}\right) .
\end{aligned}
$$

The learning curve is represented as a non-linear and non-convex formulation in MERGE5 according to equation (5), which is based on cumulative production and the knowledge stock relative to the starting year ${ }^{2}$ :

$$
G C_{k, t}=\frac{G C_{k, 0} \cdot C P_{k, t}^{-b} \cdot K S_{k, t}^{-c}}{C P_{k, 0}^{-b} \cdot K S_{k, 0}^{-c}}=G C_{k, 0} \cdot\left(\frac{C P_{k, t}}{C P_{k, 0}}\right)^{-b} \cdot\left(\frac{K S_{k, t}}{K S_{k, 0}}\right)^{-c} .
$$

The economic production variable $Y_{r t}$ of MERGE must be reformulated to take into account the annualized R\&D spending and the subsidies in learning investments:

$$
\begin{aligned}
Y_{r t}= & C_{r t}+I_{r t}+E C_{r t}+D C_{r t}+N T X_{r t}+R D_{r t} \\
& -\sum_{k} S P E_{r k t} \cdot s d y_{k, 0}\left(\frac{C P_{k, t}}{C P_{k, 0}}\right)^{-b} \cdot\left(\frac{K S_{k, t}}{K S_{k, 0}}\right)^{-c} .
\end{aligned}
$$

\footnotetext{
${ }^{2}$ The model is solved with the CONOPT3 optimizer using the procedure described in Manne and Barreto (2004). 
We assume that in the periods 2010-2030, part of the costs for the two technologies (i.e. $s d y$ in Equation (6) above) is either subsidized or is anyhow introduced in niche markets without charge. This cost consists of a maximum of 9 US $\$ / G J$ for the non-electric systems and 75 mills/kWh for the LBDE technology at the starting point of their introduction (e.g., in the year 2005), and diminishes strongly as the generation costs follow the autonomous reduction rate and the learning curves. Additionally, extra R\&D spending is made available in the same periods to demonstrate technical feasibility, to reduce further the generation cost of carbon-free technology, and to accelerate their introduction.

\subsubsection{The role of technological learning in $\mathrm{CO}_{2}$ stabilization}

Several scenarios related to $\mathrm{CO}_{2}$ emission control are presented as illustrations of the results generated by this version of MERGE. Apart from the business-as-usual (BaU), cases where $\mathrm{CO}_{2}$ emissions are not limited, we have considered the implications of stabilizing atmospheric $\mathrm{CO}_{2}$ concentration to $450 \mathrm{ppmv}$ and a case with $2{ }^{\circ} \mathrm{C}$ maximum temperature change. All three scenarios are assessed with and without ETL options. The baseline case is designated by BaU$\mathrm{N}$, where technological change is exogenous, whereas BaU-L denotes the baseline case where LBD applies, and BaU-S designates the case where the TFLC and learning subsidies apply. The database for the baseline cases reflects the original data of MERGE5, while the stabilization cases consider policies to abate all greenhouse gases (GHGs) and adopt carbon sinks.

In the BaU-N case, the world GDP grows more than 11 times (i.e., to US\$365 trillion) between 2000 and 2100; but primary-energy supply and carbon emissions are strongly decoupled from economic growth and increase by only 3.8 times (i.e., to 1,430 EJ of primary energy per annum and $22.3 \mathrm{GtC} / \mathrm{yr}$ carbon emissions in 2100). In the $\mathrm{BaU}(-\mathrm{N},-\mathrm{L})$ cases, the global $\mathrm{CO}_{2}$ concentration increases to $750 \mathrm{ppmv}$, while the global average temperature rise is $2.48^{\circ} \mathrm{C}$. Most of the economic growth occurs in economies (currently) in transition and in developing countries.

Policies that support technological learning result in a strong contribution of renewables in meeting non-electric-sector demands. This shift enhances the use of non-electric backstop technologies for which a learning rate of $15 \%$ cost reduction per doubling of production, and a $10 \%$ decrease per doubling of the knowledge stock has been assumed. For the BaU-S case, therefore, renewable-energy sources contribute $39 \%$, coal $45 \%$, nuclear $2 \%$ of the energy mix, with oil and gas contributing the remaining $14 \%$ compared to a $56 \%$ contribution for coal in the BaU-N scenario. Learning in the BaU-L case reduces emissions to $20.4 \mathrm{GtC} / \mathrm{yr}$ in the year 2100.

Properly applied R\&D policies could result in a significant cost reduction of energy and carbon control costs. The scenarios where the atmospheric $\mathrm{CO}_{2}$ concentration is held to 450 ppmv assume that efficient strategies will be adopted worldwide and a full-scope transfer of "know-how" will take place. Under these circumstances, the following conclusions can be made: First, the cumulative and undiscounted GDP losses because of the introduction of carbon-stabilization constraints at $450 \mathrm{ppmv}$, in relation to the cumulative baseline-GDP production, are low. For example, below $1.26 \%$ in the base case, while with LBD and LBS favorable policies the GDP losses ${ }^{3}$ are less than $0.42 \%$ (Figure 1). Secondly, the marginal costs related to carbon stabilization are also reduced to a fraction of the marginal cost without learning (Figure 2), but remain significant for the case of the $450 \mathrm{ppmv}$ atmospheric carbon limit.

\footnotetext{
${ }^{3}$ Cumulative GDP refers to the net present value (NPV). The discount rate is $5 \%$.
} 


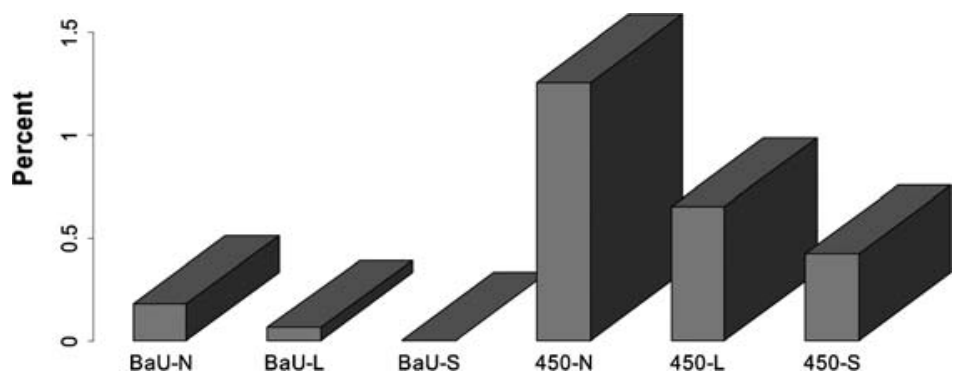

Fig. 1 Cumulative and discounted GDP losses for the stabilization cases of carbon concentration, relative to the GDP of BaU-S. The cumulative and undiscounted GDP losses are significantly reduced in the case of LBD and LBS. For the 450-ppmv cases, the cumulative loss of below $1.26 \%$ in the base case, while with LBD and LBS favorable policies the GDP losses are less than $0.42 \%$ (e.g., in LBD \& LBS case)

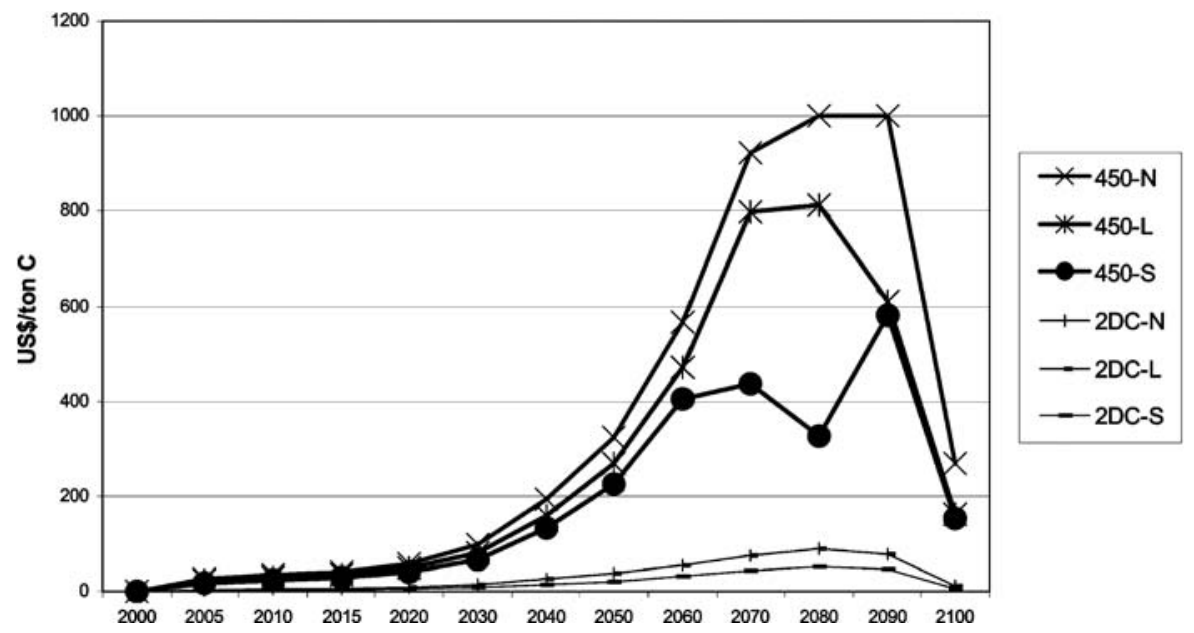

Fig. 2 The marginal costs of carbon control are significantly reduced in the case of RD\&D policies

\subsection{Technological learning in the energy-system GMM model}

Technological learning is an important mechanism influencing the technology dynamics of the global energy system. Market experience is one of the main channels to accumulate technology learning, leading to cost reductions and performance improvements that could allow new technologies to become competitive in the long term. Demonstration and deployment (D\&D) programs play an important role in enabling the accumulation of valuable market experience for cleaner and more efficient emerging energy technologies and are key policy instruments to stimulate their progress. Impact assessment of policy instruments is an important component of the policy-making process of, among others, the European Commission, in particular in the context of the implementation of sustainable development strategies (EC 2002). It represents a systematic effort to evaluate changes on sustainability indicators due to a policy measure (EC 2002). This section provides some insights into the effects of D\&D programs in achieving diffusion of new technologies and their impact on indicators of sustainability of the global energy system in the areas of climate change and security of 
energy supply. The analysis has been conducted with an extended version of the "bottom-up" energy-systems GMM model (Barreto and Kypreos 2004a,b; Rafaj et al. 2005). GMM is a global, multi-regional optimization model that allows a detailed representation of energy supply and end-use technologies. The GMM model endogenizes one-factor learning, or experience, curves (hereon referred to as 1FLC), where cumulative installed capacity is used as a proxy for accumulated experience. ${ }^{4}$

For this analysis, the energy-system GMM model has been substantially extended (Barreto and Kypreos 2004b). Marginal abatement curves for two main non- $\mathrm{CO}_{2}$ gases $\left(\mathrm{CH}_{4}\right.$ and $\left.\mathrm{N}_{2} \mathrm{O}\right)$ have been incorporated. Among others, a clusters approach to technology learning, based on the "key technology" approach, where key learning components (e.g. a gas turbine) are shared by several technologies (e.g. gas combined-cycle, IGCC, etc), has been implemented. The model is calibrated to year-2000 international energy statistics and spans through the time horizon 2000-2050 with ten-year time steps. A discount rate of 5\% is used in all calculations reported herein (see Barreto and Kypreos (2004b) for a more detailed description of the model).

\subsubsection{Methodology}

In order to assess the impact of a given policy instrument, we examine the incremental change in a number of sustainability indicators when the policy instrument, D\&D programs in this case, is applied relative to the costs of application of the instrument. In what follows, this measure is referred to as the "impact" of the policy instrument and is defined as follows:

$$
\text { Impact }=\frac{\Delta \text { Indicator }}{\text { Instrument Cost }} .
$$

In conducting this analysis, the methodology of D\&D "shocks" has been applied. D\&D shocks are one-time increments in the installed cumulative capacity, a proxy for the accumulated experience of a given key learning component, at the beginning of the time horizon. Essentially, a D\&D shock will let the key component move down its learning curve, i.e. by increasing the installed cumulative capacity it will reduce the corresponding specific investment costs as illustrated in Figure 3.

\subsubsection{Simulation results}

In the illustrative results presented here, standard D\&D shocks of US\$ 10 billion size have been applied to the GMM model during the first time period when the technology is assumed to be available (equivalent to US\$1 billion per year during a 10-year time period). A standard D\&D shock size has been chosen in order to be able to compare the effects of D\&D shocks for different technologies on a common basis. This gives a policy maker a clearer notion of what the impacts on sustainability indicators would be if a given sum of money is invested on a D\&D program for a particular technology. The impact of D\&D shocks on selected technologies on two sustainability indicators related to climate change and security of energy supply, namely global $\mathrm{CO}_{2}$ emissions and global resource-to-production $(\mathrm{Ru} / \mathrm{P})$ ratio for oil (measured in years) is illustrated in Figures 4 and 5. Both indicators are reported for the

\footnotetext{
${ }^{4}$ For this 1FLC representation, a piece-wise linear approximation of the learning curve is implemented through Mixed Integer Programming (MIP) techniques in the GMM model. For a detailed description (see Barreto and Kypreos 2004a).
} 


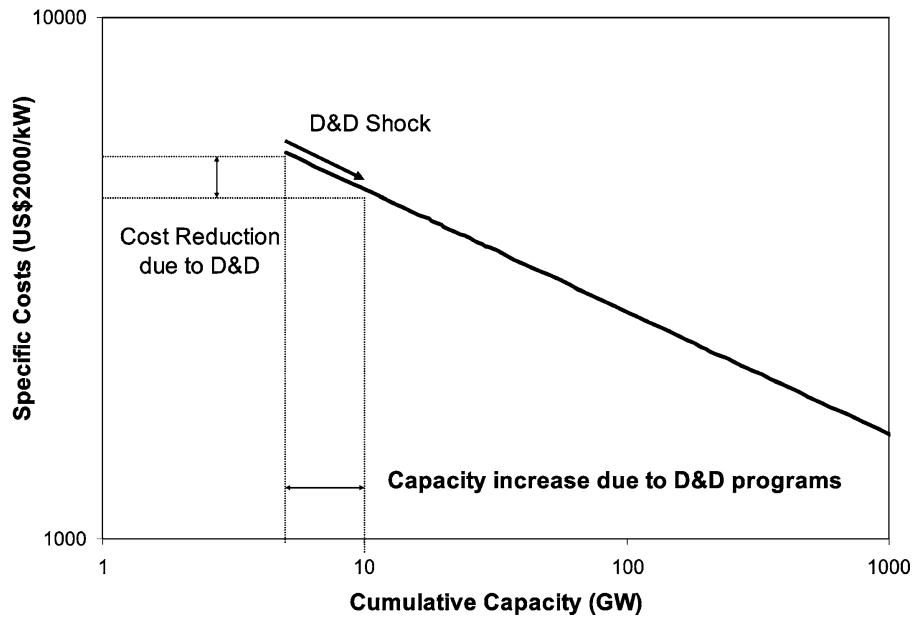

Fig. 3 Schematic illustration of the effect of demonstration and deployment (D\&D) programs ("shock") on the learning curve of a key component

Fig. 4 Impact of selected D\&D shocks on the global $\mathrm{CO}_{2}$ emissions in the year 2050

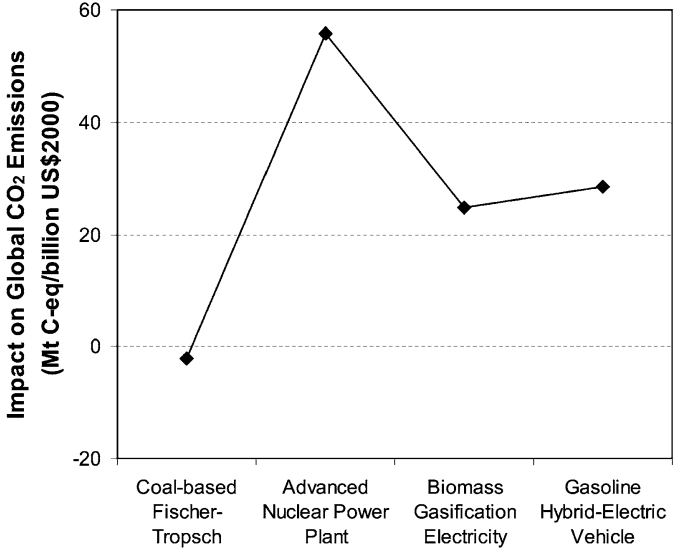

year 2050. For the estimation of the global oil $\mathrm{Ru} / \mathrm{P}$ ratio only conventional resources were considered. The illustrative technologies chosen here for the D\&D shocks are as follows: Coal-based Fischer-Tropsch liquids, advanced nuclear power plants, biomass gasification power plants and gasoline hybrid-electric cars.

Impacts are measured relative to the baseline case. That is, no other policy instruments (e.g. $\mathrm{CO}_{2}$ taxes) have been assumed to be imposed on the global energy system. Notice that, by convention, positive impacts are associated with an improvement of the sustainability indicator (e.g. a reduction in $\mathrm{CO}_{2}$ emissions). As expected, positive impacts on $\mathrm{CO}_{2}$ emissions are higher for low-carbon technologies (see Figure 4). Specifically, under our assumptions, advanced nuclear power plants achieve the highest positive impact on $\mathrm{CO}_{2}$ emissions. Coal-based Fischer-Tropsch liquids, on the other hand, have a negative impact on $\mathrm{CO}_{2}$ emissions. The set of illustrative technologies chosen here shows positive impacts on the global petroleum resource-to-production ratio (see Figure 5).

黛Springer 
Fig. 5 Impact of selected D\&D shocks on the global resources-to-production $(\mathrm{Ru} / \mathrm{P})$ ratio of oil in the year 2050

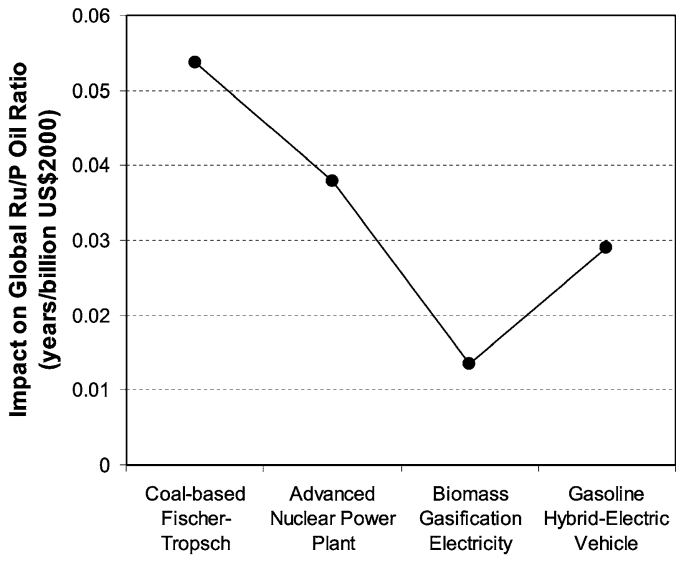

Among other factors, the clusters approach to technology learning may have a significant impact on the results, because of the interactions it creates between technologies. When a given technology receives a D\&D shock, this implies a stimulus for the installations of its learning and non-learning components. Through the action of clusters, the D\&D "shock" is a stimulus to deploy other technologies sharing the key learning components as well. Demonstration and deployment (D\&D) programs constitute an important policy measure for accumulating valuable market experience that could stimulate technology learning of emerging, cleaner and more efficient energy technologies. Specifically, a strategic management of niche markets, where a technology may be attractive due to specific advantages or particular applications, may stimulate its diffusion process.

\section{Modeling strategic competition}

The second part of this paper addresses another strand of problems where strategic behavior of the agents should be taken into account. They concern the implementation of international emissions trading systems either in the Kyoto or post-Kyoto frameworks.

Under the Kyoto agreement, the states of the former Soviet Union (FSU) have received emissions quotas based on their 1990 performances. After the collapse of Soviet Union these quotas have yield large levels of almost zero-cost abatement opportunities that have been called "hot air" in the negotiators jargon. This gives to Russia in particular a potential domination of the emissions trading market. However another source of low cost abatement opportunities exists in developing countries, in particular China. The stage is therefore set for a sort of oligopolistic competition between between these two potential large sellers of emissions rights. In the first subsection below we shall briefly review a two-level dynamic game model that has been developed to evaluate the possible effects of this competitive structure on the evolution of carbon price in the Kyoto emissions permit market scheme Bernard et al. (2005); Haurie and Viguier (2003).

Another possibility of strategic behavior appears in the implementation of the emissions trading scheme in the European Union (EU) when each country has to decide how to allocate the quotas to different sectors of the economy. Due to market imperfections associated with the fiscal systems and also with the fact that the whole economy is not allowed to take part 
in the trading system, the way countries allocate the quotas is not indifferent. Furthermore, because of trade effects the welfare gains obtained from the allocations decided by the different countries are interdependent. This defines a gaming situation, described in the second subsection, that has been addressed by Viguier et al. (2006) in a two-level $m$-matrix game model for which correlated equilibrium solutions can be computed to evaluate the actions of the dominating countries in EU. ${ }^{5}$

In the third subsection below we present the extension of this game theoretic framework to the possible post-Kyoto negotiations that should take place once one knows the real extent of the global climate change process and hence the limits to impose on global GHG emissions over the rest of the century. An international agreement should be "self-enforcing" and this calls for a set of national policies that constitute a Nash equilibrium for a strategic game. We present below a dynamic game model where a set of nations bound to satisfy collectively a constraint on global emissions play a noncooperative game on the definition of their relative emission quotas.

These three game theoretic models share the same two-level structure. At the lower level one represents the world economy in the form of a computable general economic equilibrium (CGE) model. Emissions rights or quotas are the strategic variables whereas emissions trading is the result of a market equilibrium. These two-level games represent a step in the direction of a better representation of the strategic opportunities that are inherent to the implementation of an international emissions trading system.

\subsection{A two-level dynamic game of "hot-air" competition}

\subsubsection{The model}

Bernard et al. (2005) have proposed a deterministic dynamic game model to show the possible competition between Russia and entrant developing countries on the emissions market. They formalized the "hot-air" competition problem as a dynamic multistage game for which they computed an open-loop Nash equilibrium solution (Başar and Olsder 1989; Dockner et al. 2000; Rosen 1965). ${ }^{6}$ The model has the structure of a Cournot duopoly model with depletable resource stocks representing the banked emission permits. These stocks can be replenished via an abatement activity. The discrete time model has periods $t=0,1, \ldots, T$. Each player controls a dynamical system described as follows:

- Player 1: It represents Russia which benefits from "hot air". The following variables and parameters enter into the description of Player 1:

$\beta_{1}$ : discount factor for player 1

$x_{1}(t)$ : stock of permits that are banked by player 1 at time $t$

$u_{1}(t)$ : permits that are supplied by player 1 at time $t$

$h(t)$ : "hot air" input for player 1 at time $t$

$q(t)$ : emissions abatement for player 1 at time $t$

$c_{1}\left(q_{1}\right)$ : cost function for emissions abatement

$\pi_{1}$ : terminal value of the stock of permits

In the above list of parameters and variables, the time function $h(t)$, which is exogenously given, represents the amount of credited "hot air" emissions abatement at each

\footnotetext{
${ }^{5}$ The correlated equilibrium approach was also applied to climate negotiations in Forgo et al. (2005).

${ }^{6}$ For a comparison of open-loop and feedback game outcomes (see Ciscar and Soria 2004). 
time $t$. We assume $h(t) \geq 0$ if $t<T$ and $h(T)=0$. The dynamical system representing Player 1 is defined as follows:

$$
\begin{aligned}
\max \quad \sum_{t=0}^{T-1} \beta_{1}^{t}\left[p(t) u_{1}(t)-c_{1}\left(q_{1}(t)\right)\right]+\beta_{1}^{T} \pi_{1} x_{1}(T) \\
\text { s.t. } \quad x_{1}(t+1)=x_{1}(t)-u_{1}(t)+h(t)+q_{1}(t) \\
x_{1}(0)=0 \\
u_{1}(t) \geq 0 \\
x_{1}(t) \geq 0
\end{aligned}
$$

- $\quad$ Player 2: It represents a large developing country (typically China) which may develop its own market of emission rights instead of the CDM scheme. The following variables and parameters enter into the description of Player 2:

$\beta_{2}$ : discount factor for player 2

$x_{2}(t)$ : stock of permits that are banked by player 2 at time $t$

$u_{2}(t)$ : permits that are supplied by player 2 at time $t$

$q_{2}(t)$ : emissions decrease due to Player 2 abatement activities

$c_{2}\left(q_{2}\right)$ : cost function for emissions abatement

$\pi_{2}$ : terminal value of the stock of permits

$\theta$ : period at which China may join the market

The dynamical system representing Player 2 is defined as follows:

$$
\begin{aligned}
\max \sum_{t=0}^{T-1} \beta_{2}^{t}\left[p(t) u_{1}(t)-c_{2}\left(q_{2}(t)\right)\right]+\beta_{2}^{T} \pi_{2} x_{2}(T) \\
\text { s.t. } \quad x_{2}(t+1)=x_{2}(t)-u_{2}(t)+q_{2}(t) \\
x_{2}(0)=0 \\
u_{2}(t) \geq 0 \\
u_{2}(t) \\
x_{2}(t) \geq 0 \quad \forall t \in[0, \theta] \text { where } \theta<T
\end{aligned}
$$

- Price of permits: An inverse demand law describes the market clearing price for permits in Annex B countries.

$$
p(t)=D\left(u_{1}(t)+u_{2}(t)\right)
$$

This demand function is derived from the competitive equilibrium conditions for the Annex B countries in each period.

We look for a Nash equilibrium solution, assuming an open-loop information structure (the reader is referred to Başar and Olsder (1989) for a presentation of the information structures in dynamic games). It means that the competing agents select an open-loop control, that is a time schedule for their supply of emission permits over the planning horizon $0,1, \ldots, T-1$. The optimality conditions are obtained by formulating the first order Nash equilibrium conditions. 
The search for an equilibrium solution is then formulated as a nonlinear complementarity problem for which efficient algorithms exist.

\subsubsection{Simulation results}

For the numerical experiments, we use simulation results of a CGE model, GEMINI-E3, and a partial equilibrium model of the world energy system, POLES, (Criqui 1996). In order to investigate the impact of strategic behaviors on the markets for tradable permits, we compare a case where Russia is the only supplier in the market, and thus acts as a monopoly with a case where Russia and China play the emission permits game described in the previous section.

In the two cases, the demand of emission permits is assessed under a "Kyoto Forever" scenario, implying that Annex B countries (except the US) are committed to a constant level of emissions over time - the one sets in the Protocol - while non-Annex B countries remain free of any commitment. We suppose that emission permits are freely tradable in the international market. It is also assumed that Russia can freely trade its hot air, and that emission permits can be banked without constraint. The terminal value of the stock of permits is supposed to be equal to zero. We apply a 5\% discount rate. Finally, we assume no transaction costs in the two base cases. The impacts of China's participation in the post-Kyoto regime, and transaction costs on the emission markets, will be assessed further.

Russia banks a large portion of "hot air" (88\% in 2010) in the monopoly case in order to maximize its trading gains. Since the permits demand is relatively inelastic to prices in GEMINI-E3, there is a rather high incentive for Russia to act as a monopolist, and to let prices go up by restricting its supply of permits. In the monopoly case, the permit price rises from $140 \$ / \mathrm{tC}$ in 2010 to $213 \$ / \mathrm{tC}$ in 2030 (Figure 6). As expected, the amount of permits banked by Russia decreases when it has to compete with China in $\mathrm{CO}_{2}$ emission markets. When revenues from permits sales depend on its own supply and the other country's supply (duopoly scenario), the Nash-Cournot equilibrium price is much lower than the monopoly price. Set at $90 \$ / \mathrm{tC}$ in 2010 , the permit price rises slowly to $128 \$ / \mathrm{tC}$ in 2030 .

\subsection{A correlated equilibrium solution to the EU emission quotas allocation game}

In this section we analyze another risk of strategic behavior of the countries involved in the implementation of $\mathrm{CO}_{2}$ markets: a manipulation of the initial allocation of emission quotas

Fig. 6 Price of $\mathrm{CO}_{2}$ permits (Monopoly \& Duopoly cases)

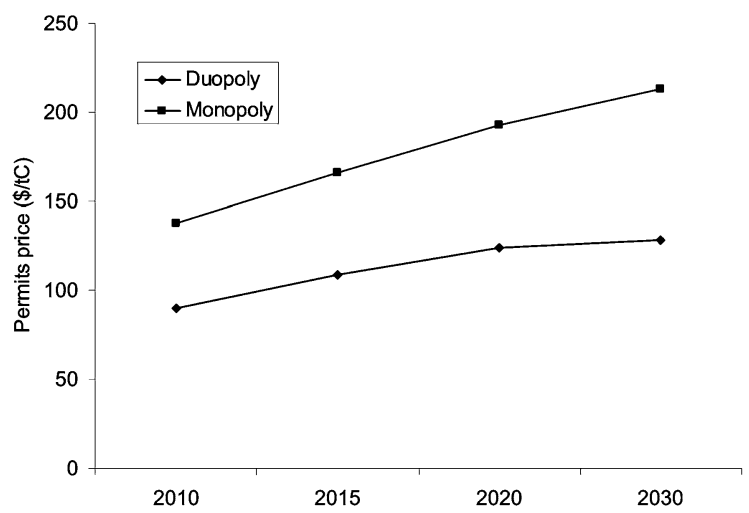


in order to subsidize their energy-intensive industries. One should represent the problem as a non-cooperative game and look for some equilibrium solution. As explained in Viguier et al. (2006), this game has a two-level structure since the strategies selected by the players have consequences that are calculated from a computable general equilibrium model. The upper-level game is represented as an $M$-matrix game, where $M$ is the set of active countries and where the payoffs are obtained by running a CGE model (i.e. GEMINI-E3) under the configurations associated with the different possible strategy choices. The upper-level game will be solved for the characterization of the set of correlated equilibria (see Aumann 1974).

\subsubsection{The model}

The games is played by countries or groups of countries that may manipulate the initial allocation of emission quotas. The strategies are the different (contrasted) allocation schemes that could result from individual decisions over quotas allocation. The payoffs of the game are the welfare gains (-losses) for each player resulting from Kyoto emission targets under the EU-wide trading regime. Again, we say that these games have a two-level structure since the strategies selected by the players have consequences that are calculated from a computable general equilibrium model. The upper-level game is represented as an $M$-matrix game, where $M$ is the set of active countries and where the payoffs are obtained by running GEMINI-E3 under the configurations associated with the different possible strategy choices. The upperlevel game is solved for the characterization of the set of correlated equilibria. The game in strategic form is defined by $\Gamma=\left(M,\left(S_{j}\right)_{j \in M},\left(u_{j}\right)_{j \in M}\right)$ where $M$ is the set of players, $S_{j}$ is the set of our strategies of player $j$ and $u_{j}: \prod_{i \in M} S_{i} \rightarrow \mathbf{R}$ is the payoff function for player $j$. Let us denote $\mathcal{S}=\prod_{i \in M} S_{i}$ and $\mathbf{s}=\left(s_{j}\right)_{j \in M} \in \mathcal{S}$. A correlated equilibrium is defined by a probability distribution on $\mathcal{S}, \pi(\mathbf{s}) \geq 0, \sum_{\mathbf{s} \in \mathcal{S}} \pi(\mathbf{s})=1$ such that the following inequalities hold

$$
\sum_{\mathbf{s} \in \mathcal{S}} \pi(\mathbf{s}) u_{j}(\mathbf{s}) \geq \sum_{\mathbf{s} \in \mathbf{S}} \pi(\mathbf{s}) u_{j}\left(\mathbf{s}_{-j}, \sigma_{j}\right), \quad \forall j \in M, \forall \sigma_{j} \in S_{j}
$$

where

$$
\left(\mathbf{s}_{-j}, \sigma_{j}\right)=\left(s_{i}, \ldots, s_{j-1}, \sigma_{j}, s_{j+1}, \ldots, s_{m}\right)
$$

and $M=1, \ldots, m$.

The interpretation can be the following: through a preplay communication scheme the agents may exchange signals that sum up to each player receiving a recommendation to play a given strategy. The probability $\pi(\mathbf{s})$ is affected to the event: the vector $\mathbf{s}$ is recommended as a way to play the game. We have to realize that, in this interpretation, each player knows only the recommendation to play that concerns him. The inequalities (20) express the fact that a player has no incentive to play other than as recommended.

In brief we could view a correlated equilibrium either as the result of playing a game where a mediator sends private information to each player, in the form of a recommendation to play a given strategy, or as the result of the use of communication strategies by the players, where each player would send reports to the other players (and receive reports from the others) before deciding what to do. We can see the relevance of this scheme in the context of EU-wide negotiation for the implementation of a tradable emission permit scheme.

It is well known that the set of correlated equilibria in an $M$-matrix game is closed and compact and can be characterized through the solution of linear programs. The set of 
correlated equilibria contains the set of Nash equilibria. Therefore, if this set of correlated equilibria reduces to a singleton, it is the unique Nash equilibria for the game.

\subsubsection{Simulation results}

The allocation of $\mathrm{CO}_{2}$ emission quotas in the implementation of the EU-wide emission trading market can be viewed as an example of a "permits allocation game". Viguier et al. (2006) represent this situation as an $M$-matrix game, where the strategic players are Germany (DEU), the United Kingdom (UK), Italy (ITA), and the rest of the European Union (REU). We assume that these regions may choose among four different rules to allocate emission allowances across economic sectors:

1. Grandfathering (GF): Emission allowances are allocated among sectors according to their historical emissions taking into account a global target of emissions reduction at the national level;

2. Historical emissions (HE): The total number of allowances allocated to a given trading sector is determined by its share in each Member Stateís emissions from economic sectors included in the trading scheme emitted in a particular year (e.g. 2001), multiplied by total allowable emissions for the economy;

3. Domestic Tax-based(DT): Sectoral allowances correspond to the ones that would occur if a uniform carbon tax were to be implemented at the domestic level;

4. European Tax-based (ET): Sectoral allowances correspond to the ones that would occur if a uniform carbon tax were to be implemented at the European level.

We simulate three different games with four players and three strategies. In Game 1, one assumes that the reference rule for quotas allocation corresponds to the one equalizing marginal abatement costs across sectors at the domestic level (DT). We assess the incentive for EU countries to deviate from the DT allocation by giving 10 percent more (or less) quotas to the trading sector. In Game 2, the players can choose among more contrasted strategies. We allow EU countries to deviate a little bit more from the DT approach by giving more (GF) or less (e.g. ET in Germany) quotas to the trading sector. In Game 3, the only way for EU countries to strategize on the allocation of quotas is to give more quotas to the trading sector; the GF approach corresponds to a lower deviation from the ET rule than the HE approach.

In our numerical experiments it turns out that the games have a unique correlated equilibrium which then corresponds to a unique Nash equilibrium in pure (instead of mixed) strategies (see Table 1). The equilibria are always different from the competitive equilibrium solutions, where the different regions would play the same DT strategy. Germany, which is the main supplier of emission allowances, tends to rely on the domestic tax-based approach (DT) but the other regions, which are permits buyers, have an incentive to depart from this approach to maximize their own payoffs. The outcomes of the non-cooperative equilibria

Table 1 Unique correlated equilibria

\begin{tabular}{llll}
\hline & Game 1 & Game 2 & Game 3 \\
\hline Germany & DT & DT & DT \\
UK & DT-10 & GF & GF \\
Italy & DT+10 & DT & HE \\
Rest of EU-15 & DT+10 & GF & GF \\
\hline
\end{tabular}


Table 2 Payoffs in correlated equilibria versus cooperative equilibria (in million dollars)

\begin{tabular}{lrrrrrrrr}
\hline & \multicolumn{3}{c}{ Cooperative equilibria } & & \multicolumn{3}{c}{ Correlated equilibria } \\
\cline { 2 - 3 } \cline { 7 - 8 } & Game 1 & Game 2 & Game 3 & & Game 1 & Game 2 & Game 3 \\
\hline Germany & 1254 & 1308 & 953 & & 599 & 808 & 526 \\
UK & -1646 & -1807 & -1526 & & -1880 & -2090 & -1933 \\
Italy & -2665 & -2854 & -2726 & & -2614 & -2844 & -2709 \\
Rest of EU-15 & -4384 & -4578 & -4482 & & -4072 & -4117 & -4095 \\
Total & -7442 & -7931 & -7781 & & -7967 & -8244 & -8211 \\
\hline
\end{tabular}

are globally lower than what the players would obtain by playing the cooperative solution (see Table 2). There is no strict dominance of the correlated equilibria by the cooperative solutions with equal weight. Germany and the United Kingdom are always worse off with the non-cooperative solution but Italy and the rest of Europe are better off. Italy and the other EU countries have thus an incentive to depart from the cooperative solution. But this incentive to act strategically is relatively weak since strategic behaviors have a limited impact on the payoffs of the players.

\subsection{A normalized equilibrium solution to a Post-Kyoto game of quota negotiations}

Haurie et al. (2005a, 2005b) propose a dynamic game model for the international negotiations that will take place to share the burden of stabilizing in the long run the global $\mathrm{CO}_{2}$ concentration in the atmosphere. The model assumes a non-cooperative behavior of the parties except for the fact that they will be collectively committed to reach a target on total cumulative emissions by the year 2050. Indeed, we assume that countries have thus to agree on the long term $\mathrm{CO}_{2}$ concentration target that should be reached collectively. Given this common target each (group of) nation's respective contribution to the international effort will be guided by its own interest, if the agreement has to be self-enforcing. In that context, international emission trading might be used as a mean to reduce the economic costs of the emission constraint, and to create incentives for participation through financial transfers. Once the global goal is defined the degrees of freedom left to the players reside in the level and timing of their abatement commitments. The concept of normalized equilibrium is used to characterize a family of dynamic equilibrium solutions in an $m$-player game where the agents are (groups of) countries and the payoffs are the welfare gains obtained from economic activities, including trading of goods and emission permits. A coupled constraint is introduced to represent the needed global emissions abatement.

\subsubsection{The model}

The game is played over $T$ periods. $M$ is a set of $m$ groups of countries hereafter called players which must decide on the caps they impose on their respective global emissions of $\mathrm{CO}_{2}$ in each period. We denote $\bar{e}_{j}(t)$ the cap decided by player $j$ for period $t=1, \ldots, T$. A global limit $\bar{E}$ will be imposed on the cumulative emissions over the time horizon $T$. 
Therefore the following constraints are imposed on all players together

$$
\sum_{j \in M} \sum_{t=1}^{T} \bar{e}_{j}(t) \leq \bar{E}
$$

Let $\overline{\mathbf{e}}(t)=\left\{\bar{e}_{j}(t)\right\}_{j \in M}$ denote the vector of caps decided for all players in period $t$. The result of a global economic $m$-country equilibrium defines a welfare gain for each player, hereafter called its payoff at $t$ and denoted $W_{j}(\overline{\mathbf{e}}(t))$. Given a choice of moves $\overline{\mathbf{e}}=\{\overline{\mathbf{e}}(t) \mid: t=1, \ldots, T\}$ also called an emissions program the total payoff to player $j$ is given by

$$
J_{j}(\overline{\mathbf{e}})=\sum_{t=1}^{T} \beta^{t-1} W_{j}(\overline{\mathbf{e}}(t)) \quad j \in M .
$$

where $\beta$ is a common discount factor.

\subsubsection{Normalized equilibrium solutions}

We assume that the players behave in a noncooperative way but are bound to satisfy the global cumulative emissions constraints (22) that are consistent with a long term $\mathrm{CO}_{2}$ concentration target. We therefore use the normalized equilibrium solution concept as proposed by Rosen (1965) to deal with concave $m$-player games when coupled constraints are linking the decisions of all players. We call $\mathcal{E}$ the set of emissions $\overline{\mathbf{e}}$ that satisfy the constraints (22). We denote $\left[\overline{\mathbf{e}}^{*-j}, \bar{e}_{j}\right]$ the emissions program obtained from $\overline{\mathbf{e}}^{*}$ by replacing only the emissions program $\bar{e}_{j}^{*}$ of player $j$ by $\bar{e}_{j}$.

Definition. The emissions program $\overline{\mathbf{e}}^{*}$ is an equilibrium under the coupled constraints (22) if the following holds for each player $j \in M$

$$
\begin{aligned}
\overline{\mathbf{e}}^{*} & \in \mathcal{E} \\
J_{j}\left(\overline{\mathbf{e}}^{*}\right) & \geq J_{j}\left(\left[\overline{\mathbf{e}}^{*-j}, \bar{e}_{j}\right]\right) \quad \forall \bar{e}_{j} \text { s.t. }\left[\overline{\mathbf{e}}^{*-j}, \bar{e}_{j}\right] \in \mathcal{E} .
\end{aligned}
$$

Therefore, in this equilibrium, each player replies optimally to the emissions programs chosen by the other players, under the constraint that the global cumulative emission limits must be respected.

It has been shown by Rosen that a class of equilibria under coupled constraints, called normalized equilibria, could be obtained in the following way. Let $\mathbf{r}=\left(r_{j}\right)_{j \in M}$ with $r_{j}>0$ and $\sum_{j \in M} r_{j}=1$ be a given weighting of the different players. Assuming the required regularity we can introduce a Kuhn-Tucker (K-T) multiplier $\lambda^{o}$ for the constraint $\sum_{t=1}^{T} \bar{e}_{j}(t) \leq \bar{E}$ and form the Lagrangians

$$
J_{j}(\overline{\mathbf{e}})+\lambda^{j}\left(\bar{E}-\sum_{j \in M} \sum_{t=1}^{T} \bar{e}_{j}(t)\right)
$$

where

$$
\lambda^{j}=\frac{1}{r_{j}} \lambda^{o} .
$$


The normalized equilibrium associated with the weighting $\mathbf{r}$ is the Nash equilibrium solution for the auxiliary game with a payoff function defined for each player $j$ by (26), where the common K-T multiplier $\lambda^{o}$ is such that

$$
\begin{aligned}
& 0 \leq \lambda^{o} \\
& 0=\lambda^{o}\left(\bar{E}-\sum_{j \in M} \sum_{t=1}^{T} \bar{e}_{j}(t)\right) .
\end{aligned}
$$

This characterization has an interesting interpretation in terms of negotiation for a climate change policy. A common "tax" $\lambda^{o}$ is defined and applied to each player with an intensity $\frac{1}{r_{j}}$ that depends on the weight given to this player in the global response function. Rosen has also given conditions, called diagonal strict concavity, on the function $\sum_{j \in M} r_{j} J_{j}(\overline{\mathbf{e}})$ which ensure existence and uniqueness of the normalized equilibrium associated with the weighting r. Therefore, under these conditions, we can define a manifold of equilibria outcomes indexed over the set of possible weights $\mathbf{r}$. In general, when its relative weight $r_{j}$ increases the burden of Player $j$ in satisfying the coupled constraint diminishes and its payoff increases at equilibrium.

\subsubsection{Simulation results}

The policy scenario is built on the assumption that we are collectively committed to stabilize global $\mathrm{CO}_{2}$ concentration at no more than 550 parts per million (ppm) in order to limit global temperature rise to 2 degrees Celsius above pre-industrial levels (see Haurie et al., 2005a). The $\mathrm{CO}_{2}$ concentration target is translated into a global target on total cumulative emissions by 2050 . It is thus assumed that the countries and regions decide unilaterally on their own abatement targets under this coupled emission constraint. In this first experiment, we only consider two periods of commitment of 25 years each (2000-2025 and 2025-2050). It means that countries and regions have to take decisions on their own abatement reduction level in 2000 and $2025 .^{7}$ The payoffs are based on households surplus (payoffs) computed by GEMINI-E3 are discounted at 3\% per year, and the target is supposed to be reached through a global emissions trading system. The problem is solved by implementing an oracle based method where at each iteration the CGE, hereafter called the "oracle" is queried and returns an information consisting of (i) the evaluation of the payoff values and, (ii) the evaluation of the pseudogradient at the query point (Haurie et al. 2005a).

As explained by Rosen (1965), the unique normalized equilibrium should change with the weighting $\mathbf{r}$ of the different players. This weighting might be defined in consistency with distributive justice precludes. It could be based on population, macro-economic indicators (i.e. GDP, consumption) and/or environmental indicators (i.e. history of GHG emissions). The weighting could also reflect the negotiating power of the players. In order to explore how equilibria might change with different weights, one can assess the effect of increasing the weight of developing countries compared to a "balanced" policy case where the same weight is put on the different players. As expected, this has the effect of reducing the cost of the climate policy for developing countries (DCs) (Figure 7).

As shown on the graph, one can define a weighting that would lead to an equilibrium where DCs do not support any welfare cost. This equilibrium does not correspond to the

\footnotetext{
${ }^{7}$ Since GEMINI-E3 computes an equilibrium every year, we assume a linear emissions reduction rate for each period of 25 years.
} 


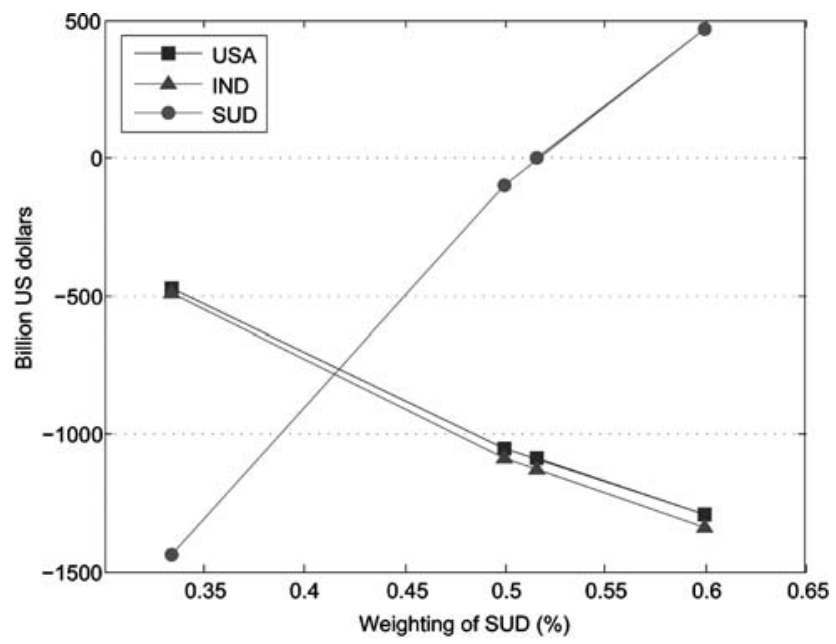

Fig. 7 The impact of changing the relative weight of SUD on discounted welfare costs for USA, other industrialized countries (IND) and developing countries (SUD), 2000-2050 (in billion USD).

burden sharing option, advocated by IEA (2002) and Philibert and Pershing (2001), where the baseline emissions are given to the DCs (also called the "non-constraining target" option). It is a situation where the costs of meeting the domestic reduction targets are balanced by the gains associated with the selling of emission permits. Based on GEMINI-E3 estimates, we find that DCs might preserve their welfare growth while accepting a $20 \%$ reduction target (compared to their baseline). As shown in Figure 7, DCs are better off when their weight increases above 53\%. They might voluntarily accept to reduce their GHG emissions in order to participate in international emission trading. This result tend to show that market-based environmental instruments might be used as a good incentive for future global climate policy.

\section{Conclusion}

This paper has presented selected examples of attempts to represent endogenous technological learning and imperfect competition effects in different modelling frameworks. In the examples developed in this paper, we have shown the potential effects of strategic investments on R\&D activities and demonstration and deployment (D\&D) programs in climatechange mitigation policies quantified with perfect-foresight models. In addition, we have used game-theoretic models of Kyoto protocol implementation to illustrate the decrease in cost-effectiveness due to the possible strategic behaviour of powerful agents. Specifically, we highlight the fact that the conclusions obtained from models based on the pure competition paradigm can be far from those that could result from strategic behavior of governments in the concerned countries. Although these issues have been dealt with separately in our studies, in reality both represent important elements affecting the architecture and success of international climate-policy agreements. Moreover, strategic decisions by important global players in one area could affect the other as well. Examining the two topics in a common framework could be a promising avenue for further work. For instance, the interplay between R\&D activities and climate change cooperation can be considered together in a game-theoretic approach (e.g. Buchner et al. 2005; Kemfert 2005). 
The main results of our analysis can be summarized as follows:

- The endogenization of experience curves represents an advance in the modeling of technological change in energy-system models, capturing the early investments required for a technology to progress and achieve long-term cost competitiveness in the marketplace (Messner 1997). Our analysis illustrates the role that early investments on R\&D activities and demonstration and deployment (D\&D) programs could play in supporting the development and diffusion of cleaner technologies in the long term. Public-private partnerships and international co-operation on these topics could be useful to share the risks and costs of clean technology development and diffusion. Our results highlight the importance of these two policy instruments as key strategic elements in climate-change mitigation strategies, which must be designed such that they encourage technological innovation and progress and enable a transition in the long run towards a cleaner, more efficient, and supply secure technological path.

- As a consequence of the U.S. withdrawal of the Kyoto Protocol, low-cost countries (i.e. Russia) may have a strong incentive for strategic behavior on the $\mathrm{CO}_{2}$ market; however, our simulations show that this market power will ultimately depend on developing countries' strategies in future commitment periods.

- High-cost countries might be tempted to act strategically in climate policy implementation, and to favor their domestic industry through the initial allocation of emissions quotas; when the emissions markets are imperfect (i.e. some sectors are excluded from the EU emissions trading system), these non-cooperative behaviors increase the global cost of the carbon constraint.

- The Post-Kyoto negotiation should focus on the global GHG concentration target to be met collectively and the implementation of a world emission trading regime; Once countries and regions agree on the coupled long term constraint, developing countries might voluntary accept emissions caps that would result from a non-cooperative equilibria in order to sell emission permits.

Acknowledgements This research has been supported by the Swiss NSF under an National Centre of Competence in Research on Climate (NCCR-climate) grant.

\section{References}

Aumann RJ (1974) Subjectivity and correlation in randomized strategies. Journal of Mathematical Economics 1:67-96

Babiker M, Criqui P, Ellerman D, Reilly J, Viguier L (2003) Assessing the impact of carbon tax differentiation in the European Union. Environmental Modeling \& Assessment 8(3):187-197

Babiker M, Reilly J, Viguier L (2004) Is international emission trading always beneficial? The Energy Journal 25(2):33-56

Başar T, Olsder G (1989) Dynamic noncooperative game theory. Academic Press, London

Bahn O, Kypreos S (2002) MERGE-ETL: An optimisation equilibrium model with two different endogenous technological learning formulations. PSI Report 02-16, Paul Scherrer Institute, Villigen

Barreto L (2001) Technological learning in energy optimisation models and the deployment of emerging technologies. Thesis no. 14151, Swiss Federal Institute of Technology Zurich (ETHZ)

Barreto L, Kypreos S (2004a) Emissions trading and technology deployment in an energy-systems "BottomUp" model with technology learning. European Journal of Operational Research 158:243-261

Barreto L, Kypreos S (2004b) Extensions to the Energy-System GMM Model for SAPIENTIA. Report to the EC-sponsored SAPIENTIA Project ENK6-CT-2002-00614, Paul Scherrer Institute, Energy Economics Group, Paul Scherrer Institute, Villigen, Switzerland

Barrett S (1997) The strategy of trade sanctions in international environmental agreements. Resource and Energy Economics 19:345-561 
Barrett S (1999) A theory of full international cooperation. Journal of Theoretical Politics 11(4):519-41

Bernard A, Haurie A, Vielle M, Viguier L (2005) A two-level dynamic game of carbon emissions trading between Russia, China, and Annex B Countries. Journal of Economic Dynamic \& Control. Preliminary Accepted for Publication

Bernard A, Paltsev S, Reilly J, Vielle M, Viguier L (2003) Russia's role in the Kyoto Protocol. Report 98, MIT Joint Program on the Science and Policy of Global Change, Cambridge MA

Bernard A, Vielle M (1998) La structure du modèle GEMINI-E3. Economie \& Prévision 5(136)

Bernard A, Vielle M (2003) Measuring the welfare cost of climate change policies: A comparative assessment based on the computable general equilibrium model GEMINI-E3. Environmental Modeling \& Assessment 8(3):199-217

Buchner B, Carraro C, Cersosimo I, Marchiori C (2005) Back to Kyoto? US participation and the linkage between R\&D and climate cooperation. In: Haurie A, Viguier L (eds) Cloupling climate and economic dynamics. Kluwer Academic Publishers, Chapt. 5

Carraro C, Siniscalco D (1996) R\&D cooperation and the stability of international environmental agreements, In: Carraro C (ed) International environmental negotiations. Kluwer Academic Publishers

Ciscar J, Soria A (2004) Kyoto and beyond Kyoto climate policy: comparison of open-loop and feedback game outcomes. In: Carraro C, Fragnelli V (eds) Game practice and the environment. Cheltenham, UK -Northampton, MA: Edward Elgar

Criqui P (1996) POLES 2.2, Technical Report, JOULE II Programme, European Commission DG XVII Science Research Development, Bruxelles, Belgium

Criqui P, Viguier L (2000) Kyoto and technology at world level: Costs of $\mathrm{CO}_{2}$ reduction under flexibility mechanisms and technical progress. International Journal of Global Energy Issues 14:155-168

Dockner E, Jorgensen S, Long N, Sorger G (2000) Differential games in economics and management sciences. Cambridge, UK: Cambridge University Press

EC (2002) Communication from the commission on impact assessment. Technical Report COM(2002) 276 Final, European Commission, Brussels, Belgium

Fishbone L, Abilock H (1981) MARKAL, a linear programming model for energy systems analysis: technical description of the BNL version. International Journal of Energy Research 5:353-375

Forgo F, Fulop J, Prill M (2005) Game theoretic models for climate change negotiations. European Journal of Operational Research 160:252-267

Germain M, Toint P, Tulkens H, de Zeew A (1998) Transfers to sustain core-theoretic cooperation in international stock pollutant control. Discussion Paper 9832, CORE

Goulder L, Mathai K (2000) Optimal $\mathrm{CO}_{2}$ abatement in the presence of induced technological change. Journal of Environmental Economics and Management 39:1-38

Hahn R (1984) Market power and transferable property rights. Quarterly Journal of Economics 99(4):753765

Haurie A, Moresino F, Vielle M, Viguier L (2005a) A coupled equilibrium model of international climate policy. Mimeo

Haurie A, Moresino F, Viguier L (2005b) A two-level differential game of international emissions trading. Annals of the International Society of Dynamic Games. To appear

Haurie A, Viguier L (2003) A stochastic dynamic game of carbon emissions trading. Environmental Modeling and Assessment 8:239-248

IEA (2002) Beyond Kyoto. Energy dynamics and climate stabilisation. Paris, France: International Energy Agency

Kemfert C (2005) Climate policy cooperation games between developed and developing nations: a quantitative, applied analysis. In: Haurie A, Viguier L (eds) Cloupling climate and economic dynamics. Kluwer Academic Publishers, Chapt. 5

Kouvaritakis N, Soria A, Isoard S (2000) Modelling energy technology dynamics: methodology for adaptive expectations models with learning by doing and learning by searching. Int. J. of Global Energy Issues 14(1/2/3/4):104-115

Kypreos S (2000) The MERGE model with endogenous technological change. In: Proceedings of the economic modeling of environmental policy and endogenous technological change workshop. Amsterdam, The Netherlands, pp. 16-17

Kypreos S (2005) Modeling experience curves in MERGE. Energy 30(14):2721-2737

Kypreos S, Bahn O (2002) A MERGE model with endogenous technological change. Environmental Modeling and Assessment 8:249-259

Loulou R, Lavigne D (1996) MARKAL model with elastic demands: application to GHG emission control, In: Carraro C, Haurie A (eds) Operations research and environmental management. Vol. 5 of The FEEM/KLUWER International series on economics, energy and environment. Kluwer Academic Publishers, pp. 201-220 
Manne A, Barreto L (2004) Learn-by-doing and carbon dioxide abatement. Energy Economics 26:621-633

Manne A, Richels R (2001) An alternative approach to establishing trade-offs among greenhouse gases. Nature 401:675-677

Manne A, Richels R (2002) The impact of learning-by-doing on the timing and costs of $\mathrm{CO}_{2}$ abatement. In: International Energy Workshop. Stanford, USA, pp. 18-20

Messner S (1997) Endogenised technological learning in an energy systems model. Journal of Evolutionary Economics 7:291-313

Philibert C, Pershing J (2001) Considering the options: Climate targets for all countries. Climate Policy $1: 211-227$

Rafaj P, Kypreos S, Barreto L (2005) Flexible carbon mitigation policies: analysis with a global multi-regional MARKAL model. In: Haurie A Viguier L (eds) Cloupling climate and economic dynamics. Kluwer Academic Publishers, Chapt. 5

Rosen JB (1965) Existence and uniqueness of equilibrium points for concave $N$-person games. Econometrica 33(3):520-534

Stavins R (1995) Transaction costs and tradable permits. Journal of Environmental Economics and Management 29:133-48

Viguier L, Vielle M, Haurie A, Bernard A (2006) A two-level computable equilibrium model to assess the strategic allocation of emission allowances within the european union. Computers \& Operations Research 33(2):369-385 